Research Article

\title{
Sauchinone Blocks Ethanol Withdrawal-Induced Anxiety but Spares Locomotor Sensitization: Involvement of Nitric Oxide in the Bed Nucleus of the Stria Terminalis
}

\author{
Yu Jiao $\left(D,{ }^{1}\right.$ Sang Chan Kim $\left(\mathbb{D},{ }^{2}\right.$ Yuhua Wang $\left(\mathbb{D},{ }^{1}\right.$ Tong Wu $\left(\mathbb{D},{ }^{1}\right.$ Haifeng Jin $\left(\mathbb{D},{ }^{1}\right.$ \\ Chul Won Lee $\mathbb{D}^{2},{ }^{2}$ Sook Jahr Park $\mathbb{D}^{2}{ }^{2}$ Bong Hyo Lee $\mathbb{D}^{2},{ }^{2}$ Hee Young Kim $\mathbb{D}^{2}, 2$ \\ Chae Ha Yang $\mathbb{D}^{2}{ }^{2}$ Zhenglin Zhao $\mathbb{D}^{3},{ }^{3}$ and Rongjie Zhao $\mathbb{D}^{1}$ \\ ${ }^{1}$ Department of Psychopharmacology, Qiqihar Medical University, Qiqihar 161006, China \\ ${ }^{2}$ Medical Research Center, College of Oriental Medicine, Daegu Haany University, Daegu 706-060, Republic of Korea \\ ${ }^{3}$ Department of Biochemistry, Qiqihar Medical University, Qiqihar 161006, China \\ Correspondence should be addressed to Zhenglin Zhao; mdj6612@163.com and Rongjie Zhao; zhao_rongjie@yahoo.com
}

Received 22 November 2020; Revised 26 March 2021; Accepted 12 April 2021; Published 5 May 2021

Academic Editor: Weicheng $\mathrm{Hu}$

Copyright ( $) 2021 \mathrm{Yu}$ Jiao et al. This is an open access article distributed under the Creative Commons Attribution License, which permits unrestricted use, distribution, and reproduction in any medium, provided the original work is properly cited.

\begin{abstract}
Both the positive (manifested by locomotor sensitization) and negative (withdrawal symptoms) reinforcing effects of ethanol $(\mathrm{EtOH})$ involve central nitric oxide (NO) signaling. Sauchinone (a bioactive lignan in Saururus chinensis) has been shown to improve methamphetamine-induced behavioral and neurochemical changes via the NO signaling pathway. Thus, this study evaluated the effects of sauchinone on locomotor sensitization and anxiety during EtOH withdrawal (EtOHW). Male adult Sprague-Dawley rats were treated with $1.5 \mathrm{~g} / \mathrm{kg} / \mathrm{day}$ of EtOH $(20 \%, \mathrm{vol} / \mathrm{vol})$ via intraperitoneal injection for 28 days, followed by a 3 -day withdrawal. During withdrawal, the rats were given intragastric sauchinone $(2.5,7.5$, or $25 \mathrm{mg} / \mathrm{kg} / \mathrm{day}) \mathrm{once}$ a day. EtOH locomotor sensitization was determined by challenging EtOHW rats with $0.75 \mathrm{~g} / \mathrm{kg} \mathrm{EtOH}$, while EtOHW-induced anxiety was assessed using the elevated plus maze (EPM). None of the three doses of sauchinone affected EtOH locomotor sensitization. However, in the EPM, treatment of EtOHW rats with sauchinone at 7.5 or $25 \mathrm{mg} / \mathrm{kg} /$ day increased both the number of entries into and the time spent in the open arms. Moreover, the two doses of sauchinone inhibited the oversecretion of plasma corticosterone during EtOHW. In the bed nucleus of the stria terminalis (BNST), EtOHW increased NO production, enhanced gene and protein expression of both inducible nitric oxide synthase (iNOS) and neuronal NOS (nNOS), and also elevated protein levels of corticotropin-releasing factor, which were all inhibited by $25 \mathrm{mg} / \mathrm{kg}$ /day sauchinone. In an in vitro experiment, sauchinone (3, 10, and $30 \mu \mathrm{M}$ ) inhibited $\mathrm{H}_{2} \mathrm{O}_{2}$-stimulated nNOS protein expression in neuronal PC12 cells. Finally, intra-BNST infusion of sodium nitroprusside, a NO donor, after sauchinone $(25 \mathrm{mg} / \mathrm{kg} /$ day $)$ administration, abolished its expected anxiolytic effect. Taken together, these results indicate that sauchinone attenuates anxiety-like behavior in rats during EtOHW but spares EtOH locomotor sensitization, and the anxiolytic effect is mediated via the NO signaling pathway in the BNST.
\end{abstract}

\section{Introduction}

Alcoholism imposes a tremendous burden on human health and society, and effective treatments are lacking [1]. Similar to other drugs of abuse, ethanol (EtOH) dependence is elicited and maintained by positive (rewarding effects) and negative (affective withdrawal symptoms) reinforcement mechanisms, which are targeted by pharmacological treatments of alcoholism [2].
Although some rewarding effects of EtOH such as euphoria and gratification in human beings are difficult to be established in animal models, some animal models have nevertheless been used to measure EtOH reward, including rodent models of behavioral and neurochemical sensitization $[3,4]$. Locomotor activity is thought to reflect the stimulant-like subjective effects of EtOH, which is putatively regarded as a component of the rewarding effects of drugs of 
abuse. Increased locomotor activity typically mirrors greater reward intensity [5]. Repeated EtOH exposure enhances locomotor activity in rodents; specifically, $\mathrm{EtOH}$ challenge evokes a much greater locomotor response during $\mathrm{EtOH}$ withdrawal (EtOHW) [6]. This phenomenon is known as locomotor sensitization and represents a behavioral analogue of the rewarding effect [7]. Moreover, locomotor sensitization is closely associated with challenge-induced sensitization of dopamine release in the nucleus accumbens during EtOHW [4, 7], a form of neurochemical sensitization characterizing the rewarding effect [8]. Thus, rodent locomotor sensitization provides a behavioral and neurochemical readout of the positive reinforcement induced by $\mathrm{EtOH}$ and is therefore useful in screening potential pharmacological agents for treating EtOH dependence.

EtOH relapse after periods of abstinence is a major barrier to successful treatment of alcoholism and affective symptoms during EtOHW, such as hyperirritability, anxiety, and dysphoria, constitute the main negative reinforcing factors driving it [9]. EtOHW-induced anxiety, as the chief complaint in alcohol clinics, appears to be the most significant emotional disturbance. Accordingly, self-medication with $\mathrm{EtOH}$ to alleviate anxiety remains the main cause for EtOH relapse [10, 11]. In rodents, anxiety-like behaviors in various behavioral tests are exhibited during EtOHW [12] and seem to trigger and facilitate EtOH seeking and selfadministration [10, 13]. Undoubtedly, preventing EtOHWinduced anxiety is a promising avenue to restrain $\mathrm{EtOH}$ relapse.

Alcoholism is fundamentally a neurocircuitry disorder; neuroadaptation within limbic brain regions involved in addiction forms the biological basis for both behavioral sensitization and withdrawal anxiety [14, 15]. Elevated dopamine in the nucleus accumbens mediates locomotor sensitization [6,9], whereas increased corticotropin-releasing factor (CRF) signaling in the bed nucleus of the stria terminalis (BNST) underlies EtOHW anxiety $[16,17]$. In turn, these neurotransmission changes seem to be maintained by neuromodulators. Nitric oxide (NO), which can serve in this capacity, is involved in both the behavioral sensitization and withdrawal anxiety associated with drugs of abuse. Pretreatment with a nonselective NO synthase (NOS) inhibitor prevents the development and expression of nicotine locomotor sensitization [18], and coadministration of a neuronal NOS (nNOS) inhibitor with EtOH blocks behavioral sensitization [19]. Furthermore, increased NO signaling heightens stress-induced CRF activity in the BNST $[20,21]$, and the degree of anxiety during morphine withdrawal positively correlates with NOS activity in the hippocampus [22]. Moreover, inhibition of NOS in the dorsal raphe nucleus attenuates EtOHW anxiety [23], and reduced production of $\mathrm{NO}$ in the hippocampus appears to mitigate amphetamine withdrawal-induced despair-like behaviors [24].

Herbs from oriental medicine provide a rich pool of bioactive candidates for drug addiction treatment [25]. Evidence from clinical and animal studies indicates that besides the ones typically used to treat neurological disorders, some herbs historically used in nonneurological diseases show potential for treating addiction-related symptoms. For example, the radix of Glycyrrhiza uralensis, an herb widely used in the detoxification and treatment of various injuries, has been reported to improve the behavioral and neurochemical disturbances caused by nicotine and methamphetamine dependence [26, 27]. Saururus chinensis, similar to G. uralensis radix, is traditionally used to treat various inflammatory diseases, such as fever, jaundice, and edema [28]. Sauchinone (Sau) is a lignan isolated from $S$. chinensis; as with its parent herb, it has anti-inflammatory, antioxidant, and anticancer effects [29, 30]. Lignans belong to a large family of polyphenols that have neuroprotective effects [31]. Previously, Sau was found to inhibit acute methamphetamine-induced hyperlocomotion, as well as the acquisition and expression of methamphetamine-conditioned place preference [32]. It also attenuated repeated methamphetamine-induced neurotoxicity in striatal dopaminergic terminals, which is associated with the negative affect $[33,34]$. Crucially, these effects were all linked to the inhibitory effects of Sau on NO production $[32,33,35]$. Since $\mathrm{NO}$ signaling plays a critical role in $\mathrm{EtOH}$ dependence, these facts give rise to an idea that Sau may have modulatory effects on $\mathrm{EtOH}$ dependence.

To test this hypothesis and to widen the pool of bioactive candidates for alcoholism treatment, in this study, the effects of Sau on both EtOH locomotor sensitization and withdrawal anxiety were evaluated in rats. Additionally, the underlying mechanisms were explored, with a focus on $\mathrm{NO}$ signaling in the BNST.

\section{Materials and Methods}

2.1. Reagents. Sau was isolated from S. chinensis, and its chemical structure was verified as described previously [30]. Briefly, dried S. chinensis (Daewon Pharmacy, Daegu, South Korea) was grinded and subjected to methanol extraction (1: 10, weight/vol) 3 times for 4 hours per time under reflux cooling and distilled under reduced pressure to obtain a methanol extract. The methanol extract was suspended in distilled water and sequentially partitioned with $n$-hexane, trichloromethane, and $n$-butanol. And the $n$-hexane fraction was further fractioned by extensive silica gel chromatography using $n$-hexane: ethyl acetate gradients to obtain Sau. An enzyme-linked immunosorbent assay (ELISA) kit for corticosterone (CORT) was obtained from Abcam (Cambridge, UK), and an assay kit for NO was purchased from Nanjing Jiancheng Bioengineering Institute (Nanjing, China). Primary antibodies against inducible NOS (iNOS), nNOS, CRF, and $\beta$-actin were supplied by Abcam, and horseradish peroxidaseconjugated secondary antibody was provided by Cell Signaling Technology (Beverly, MA, USA). Sodium nitroprusside (SNP) was purchased from Sigma-Aldrich (St. Louis, MO, USA), and polyethylene glycol (PEG) 400 was obtained from Yakuri Pure Chemical Co. (Kyoto, Japan).

2.2. Animals and Experimental Protocols. Male SpragueDawley (SD) rats (9 weeks old and weighing 280-300 g) were supplied by the Laboratory Animal Center at Qiqihar 
Medical University (Qiqihar, China). The rats were housed three per cage with food and water ad libitum. The colony was maintained on a 12:12 light/dark cycle with filtered pathogen-free air and kept between $21^{\circ} \mathrm{C}$ and $23^{\circ} \mathrm{C}$ with a relative humidity of $50 \%$. Animal experiments were carried out in accordance with the National Institutes of Health Guide for the Care and Use of Laboratory Animals; all procedures were approved by the Animal Care and Use Committee of Qiqihar Medical University (approval number: QMUAECC-2016-16).

Withdrawal from repeated intraperitoneal (i.p.), EtOH (1-3 g/kg/day for 21-28 days) has been previously demonstrated to produce locomotor and neurochemical sensitization, as well as anxiety-like behaviors, in SD rats $[4,36]$. Therefore, in this study, to induce locomotor sensitization and anxiety-like behaviors during EtOHW, rats were injected (i.p.) with $1.5 \mathrm{~g} / \mathrm{kg} /$ day of $\mathrm{EtOH}(20 \% \mathrm{vol} / \mathrm{vol}$, dissolved in saline) in their home cages for 28 days, followed by 3 days of withdrawal. During the EtOHW period, the rats received Sau $(2.5,7.5$, or $25 \mathrm{mg} / \mathrm{kg} / \mathrm{day}$, dissolved in $40 \%$ PEG) or vehicle (40\% PEG), intragastrically once a day for 3 days in their home cages.

To evaluate EtOH locomotor sensitization, rats were moved to the locomotor testing boxes immediately after the final dose of Sau. Following a 30-min habituation period, the rats were challenged with $0.75 \mathrm{~g} / \mathrm{kg}$ EtOH and then left in the boxes for an additional 60 minutes, while locomotor activities were measured (Figure 1(a)). The experimental groups were as follows: saline/vehicle/saline $(n=8)$, saline/ vehicle/EtOH $(n=8), \mathrm{EtOH} /$ vehicle/saline $(n=8), \mathrm{EtOH} /$ vehicle/EtOH $(n=8), \mathrm{EtOH} / \mathrm{Sau} 2.5 / \mathrm{EtOH}(n=8), \mathrm{EtOH} /$ Sau7.5/EtOH $(n=8)$, and EtOH/Sau25/EtOH $(n=8)$.

Another cohort of rats were tested in the elevated plus maze (EPM) $30 \mathrm{~min}$ after the last intragastric Sau dose to measure their anxiety-like behaviors. The experimental groups were as follows: saline/vehicle $(n=8)$, EtOH/vehicle $(n=8), \mathrm{EtOH} / \mathrm{Sau} 2.5(n=8), \mathrm{EtOH} / \mathrm{Sau} 7.5(n=8),=\mathrm{EtOH} /$ Sau25 $(n=8)$, and saline/Sau25 $(n=8)$. Immediately following the EPM, the animals were euthanized and decapitated. The brains were removed and stored at $-80^{\circ} \mathrm{C}$ until the BNST was excised (coordinates from bregma [37]: anterior-posterior, $-0.3 \mathrm{~mm}$; medial-lateral, $\pm 1.4 \mathrm{~mm}$; and dorsal-ventral, $-7.5 \mathrm{~mm}$ ) for subsequent ELISA, quantitative polymerase chain reaction ( $\mathrm{PPCR}$ ), and Western blot analyses. Additionally, trunk blood was collected to evaluate plasma CORT concentrations (Figure 1(a)).

2.3. Locomotor Activity Test. Locomotor activity was measured in a rectangular box $\left(60 \times 60 \times 50 \mathrm{~cm}^{3}\right)$ with floors and walls made of clear acrylic panels painted black. The box has a video camera located above the center of the floor. Rats' locomotor activity was recorded and analyzed with a video tracking system (Shanghai Xinruan Technology Co., Shanghai, China).

2.4. The EPM. Anxiety-like behaviors in rats were evaluated in the EPM [12]. Briefly, the EPM is cross-shaped and consists of two opposing open arms $(50 \mathrm{~cm}$ long $\times 10 \mathrm{~cm}$ wide) with no walls and two opposing closed arms with dark acrylic walls (40 cm high). The arms are raised $50 \mathrm{~cm}$ from the floor and monitored with a video-tracking system (Shanghai Xinruan Technology Co.). The testing room was maintained under indirect dim light $(2 \times 25 \mathrm{~W})$ to encourage rats to explore the arms. At the start of the test, each rat was placed in the center of the maze, and the number of arm entries and time spent in each arm by the rat were monitored for $5 \mathrm{~min}$. The percentages of the entries made and time spent in the open arms were calculated as follows:

$$
\begin{aligned}
& \% \text { entry }_{\text {open arms }}=\frac{\text { entry }_{\text {open arms }}}{\text { entry }_{\text {open arms }}+\text { entry }_{\text {closed arms }}} \times 100 \text {, } \\
& \% \text { time }_{\text {open arms }}=\frac{\text { time }_{\text {open arms }}}{\text { time }_{\text {open arms }}+\text { time }_{\text {closed arms }}} \times 100 .
\end{aligned}
$$

2.5. Cell Culture and Treatment. A differentiated PC12 cell line (derived from rat pheochromocytoma cells) was provided by the American Type Culture Collection (Rockville, MD, USA). The PC12 cells were cultured in Dulbecco's modified Eagle's medium (Invitrogen, Carlsbad, CA, USA) containing $10 \%$ fetal bovine serum, 50 units $/ \mathrm{mL}$ penicillin, and $50 \mathrm{mg} / \mathrm{mL}$ streptomycin that was maintained at $37^{\circ} \mathrm{C}$ in a humidified $5 \% \mathrm{CO}_{2}$ atmosphere. After the cells reached a confluence of approximately $80 \%$, they were subcultured. To determine the effects of Sau on oxidative stress-induced nNOS expression, the subcultured PC12 cells were pretreated with 3,10 , or $30 \mu \mathrm{M}$ Sau dissolved in dimethylsulfoxide (DMSO); after $60 \mathrm{~min}$, they were exposed to $75 \mu \mathrm{M} \mathrm{H}_{2} \mathrm{O}_{2}$ for 24 hours. The cells were then harvested for further biochemical assays.

2.6. Cell Viability Assay. PC12 cells were cultured in 24-well plates (density of $5 \times 10^{4}$ cells per well). The cells were stained with $0.25 \mathrm{mg} / \mathrm{mL}$ MTT for 2 hours after being treated with $75 \mu \mathrm{M} \mathrm{H} \mathrm{H}_{2} \mathrm{O}_{2}$, Sau, or their combination. The media were removed from the wells, and the formazan crystals were dissolved by adding DMSO. The absorbances were read with a microplate reader (Tecan Infinite M200; Tecan, Mannedorf, Switzerland) at $570 \mathrm{~nm}$. The relative cell viability was quantified by the following formula:

$$
\% \text { cell viability }=\frac{(\text { absorbance of treated sample })}{(\text { absorbance of control })} \times 100 \text {. }
$$

2.7. Measurement of Plasma CORT Concentrations and NO Levels in the BNST. To separate the plasma, trunk blood $(1 \mathrm{~mL})$ was mixed with $20 \mu \mathrm{L}$ ethylenediaminetetraacetic acid $(20 \mathrm{mg} / \mathrm{mL})$ in a chilled tube and centrifuged at $1,500 \times \mathrm{g}$ for $10 \mathrm{~min}$ at $4^{\circ} \mathrm{C}$. The BNST tissues were excised from the stored rat brains, homogenized in ice-cold saline $(\mathrm{pH}=7.4)$, and centrifuged at $2,500 \times \mathrm{g}$ for $15 \mathrm{~min}$ at $4^{\circ} \mathrm{C}$. The supernatants were collected. Plasma CORT concentrations were 


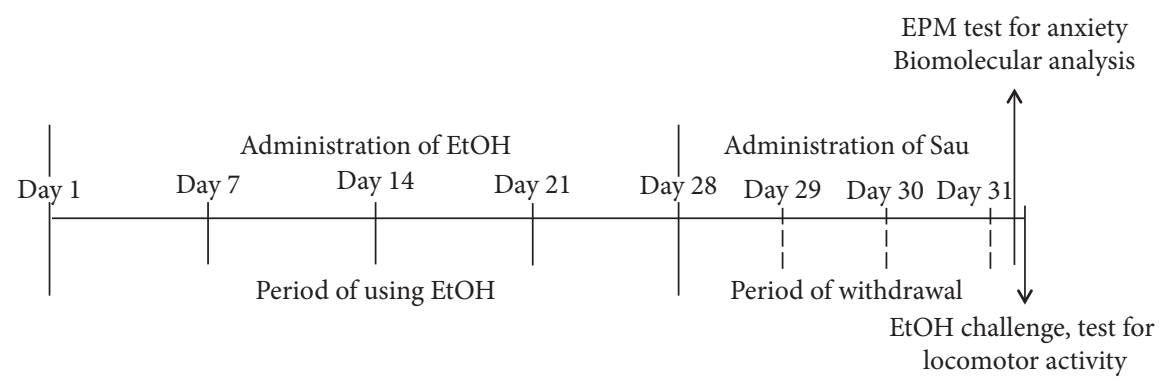

(a)
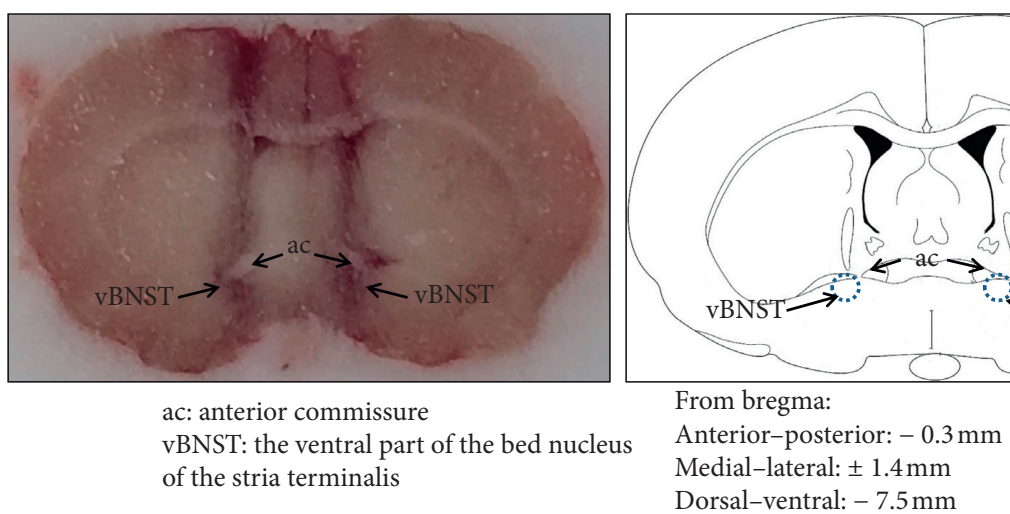

(b)

Figure 1: Schedule for EtOH withdrawal anxiety and locomotor sensitization (a) and the representative microphotograph of bilateral microinfusion positions in the BNST (b).

determined with the ELISA kit (Abcam) and expressed as $\mathrm{ng} / \mathrm{mL}$, while NO levels of the supernatants were evaluated via the assay kit and presented as $\mu \mathrm{mol} / \mathrm{g}$ protein.

2.8. Western Blot Analysis. Western blots for the proteins of interest were analyzed as described previously [26]. Briefly, BNST tissues were homogenized, while harvested PC12 cells were lysed in a radioimmunoprecipitation assay lysis buffer containing protease inhibitors. The resultant homogenates were centrifuged at $16,000 \times \mathrm{g}$ for $20 \mathrm{~min}$ at $4^{\circ} \mathrm{C}$. The supernatants were collected, and their total protein concentrations were measured with the bicinchoninic acid assay. The proteins in the supernatants were separated using sodium dodecyl sulfate polyacrylamide gel electrophoresis and subsequently transferred to polyvinylidene difluoride membranes (Millipore, Bedford, MA, USA). The membranes were sequentially incubated with the primary and secondary antibodies. Finally, the protein bands of interest were visualized with enhanced chemiluminescence (Amersham Biosciences, Little Chalfont, UK), and their densities were quantified using ImageJ software $(\mathrm{NIH}$, Bethesda, MD, USA).

2.9. qPCR Analysis. Total RNA was extracted from excised BNST tissue using TRIzol reagent (Invitrogen), and the RNA was converted into cDNA with a reverse transcription PCR kit (Promega, Madison WI, USA). qPCR analysis was carried out using a LightCycler ${ }^{\circledR}$ DNA Master SYBR Green-I kit (Roche Diagnostics, Mannheim, Germany) with a
LightCycler 2.0 (Roche Diagnostics). The primers for PCR amplification of iNOS, nNOS, and $\beta$-actin were as follows: $5^{\prime}$-CAGCTGGGCTGTACAAACCTT-3' (sense) and $5^{\prime}$ CATTGGAAGTGAAGCGTTTCG-3' (antisense) for iNOS; $5^{\prime}$-ACCCAACGT CATTTCTGTCC-3' (sense) and $5^{\prime}-$ AAGGTGGTCTCCAGGTGTGT-3' (antisense) for nNOS; and $5^{\prime}$-GTCGTACCACTGGCATTGTG-3' (sense) and $5^{\prime}$ GCCATCTCTTGCTCGAAGTC- $3^{\prime}$ (antisense) for $\beta$-actin. The results were normalized to $\beta$-actin, and relative gene expression was calculated using the $2^{-\Delta \Delta \mathrm{CT}}$ method with the following formula:

$$
\begin{gathered}
\Delta \mathrm{CT}=\mathrm{CT}_{\mathrm{NOS}}-\mathrm{CT}_{\beta \text {-actin }}, \\
\Delta \Delta \mathrm{CT}=\Delta \mathrm{CT}_{\text {treated }}-\Delta \mathrm{CT}_{\text {vehicle }}
\end{gathered}
$$

2.10. Intra-BNST Microinfusion. To determine whether the effects of Sau on EtOHW-induced anxiety were mediated by the BNST NO pathway, SNP, an NO donor, was bilaterally microinfused into the BNST $(0.1 \mathrm{nmol}, 200 \mathrm{~nL}$ per side) $30 \mathrm{~min}$ after the third Sau administration. Five minutes later, the rats were tested in the EPM. The SNP was dissolved in modified Ringer's solution (MRS) containing $150 \mathrm{mM} \mathrm{NaCl}$, $3.0 \mathrm{mM} \mathrm{KCl}, 1.4 \mathrm{mM} \mathrm{CaCl}_{2}$, and $0.8 \mathrm{mM} \mathrm{MgCl}_{2}$ in $10 \mathrm{mM}$ phosphate buffer $(\mathrm{pH}=7.2)$.

A cohort of male SD rats (280-300 g) was used in this experiment. Anesthetized rats $(50 \mathrm{mg} / \mathrm{kg}$ sodium pentobarbital, i.p.) were placed onto a stereotaxic frame, and stainless-steel guide cannulas (22-gauge) were bilaterally 
implanted with their tips $1.5 \mathrm{~mm}$ above the BNST. After implantation, the rats were individually housed and allowed to recover for at least 7 days, during which time they were administered antibiotics and analgesics to prevent infection and pain, respectively. Following recovery, the rats were subjected to the same EtOHW (or saline) and drug treatment regimen described above (Figure 1(a)).

Microinfusions were carried out by inserting a 30-gauge injector into each guide cannula; the injectors were $1.5 \mathrm{~mm}$ longer than the guide cannulas. SNP was infused over $60 \mathrm{~s}$ with a motorized syringe pump. At the end of the experiment, the injection positions of each rat were histologically verified (Figure 1(b)). The treatment groups for this experiment were as follows: saline/vehicle/MRS $(n=6), \mathrm{EtOH} /$ vehicle/MRS $(n=6), \mathrm{EtOH} / \mathrm{Sau} 25 / \mathrm{MRS}(n=6)$, and $\mathrm{EtOH} /$ Sau25/SNP $(n=6)$.

2.11. Statistical Analysis. Data are presented as the mean\pm standard error of the mean (SEM) and were checked for the normality and the homogeneity of variances before further statistical analyses. The data were analyzed using one-way analysis of variance (ANOVA) followed by the Newman-Keuls multiple comparison test, except for the BNST iNOS mRNA levels that were analyzed using a onetailed unpaired $t$-test. All statistical analyses were performed using GraphPad Prism 5.0 software (GraphPad Software Inc., San Diego, CA, USA). Significant differences were considered when $p$ values were $<0.05$.

\section{Results}

3.1. Effects of Sau on Repeated EtOH-Induced Locomotor Sensitization. In previous studies performed by our research team and other researchers, the dosages of Sau used in mice ranged from 2.5 to $30 \mathrm{mg} / \mathrm{kg}[30,32,33]$. The dose conversion ratio between mice and rats is approximately $1.43: 1$, and in a preliminary study, we found an acute $30 \mathrm{mg} / \mathrm{kg}$ dose of Sau produced small but evident behavioral changes in rats, such as small increases in grooming and gnawing; therefore, in the present study, doses of Sau at 2.5, 7.5, and $25 \mathrm{mg} / \mathrm{kg}$ /day were used.

As shown in Figure 2, on the third day following EtOH treatment cessation, a $0.75 \mathrm{~g} / \mathrm{kg} \mathrm{EtOH}$ challenge significantly increased locomotor activity in EtOH-pretreated rats compared to saline-pretreated rats $\left(F_{6,49}=25.43, p<0.001\right.$; saline/ vehicle/saline versus EtOH/vehicle/EtOH, $p<0.001$; saline/ vehicle/EtOH versus $\mathrm{EtOH} /$ vehicle/EtOH, $p<0.001$ ) and rats challenged with saline $(\mathrm{EtOH} / \mathrm{vehicle} /$ saline versus $\mathrm{EtOH} / \mathrm{ve}-$ hicle/EtOH, $p<0.001)$. The challenge dose of EtOH alone did not significantly increase locomotor activity (saline/vehicle/ saline versus saline/vehicle/EtOH, $p>0.05$ ). These data indicate that EtOH locomotor sensitization was induced during EtOHW. However, unlike what was expected, post hoc comparison tests revealed that none of the doses of Sau (2.5, 7.5 , or $25 \mathrm{mg} / \mathrm{kg} /$ day) given during the EtOHW period blocked $\mathrm{EtOH}$ locomotor sensitization $(\mathrm{EtOH} / \mathrm{vehicle} / \mathrm{EtOH}$ versus $\mathrm{EtOH} / \mathrm{Sau} 2.5 / \mathrm{EtOH}$, EtOH/vehicle/EtOH versus $\mathrm{EtOH} /$ Sau7.5/EtOH, EtOH/vehicle/EtOH versus EtOH/Sau25/EtOH,

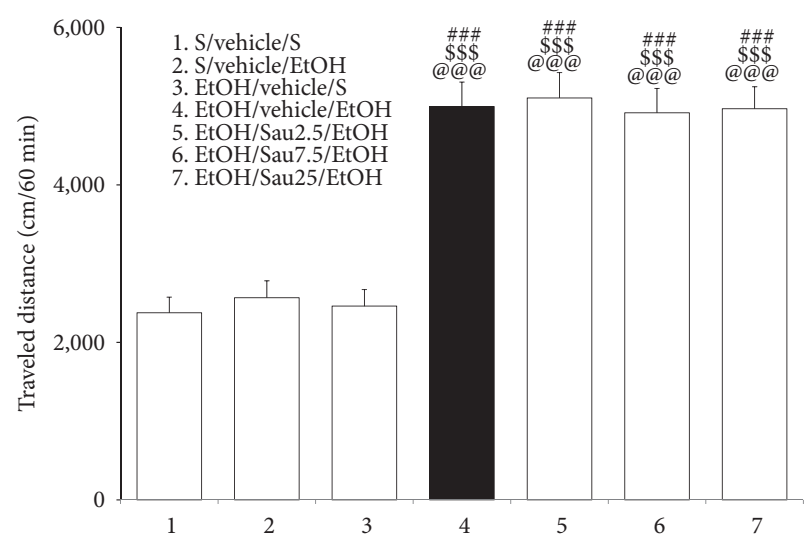

Figure 2: Effects of Sau on repeated EtOH-induced locomotor sensitization. An EtOH challenge 3 days after the cessation of repeated EtOH administrations elicited locomotor sensitization, which was unaffected by Sau treatment during EtOHW. All data are presented as means \pm SEM $(n=8)$. S, saline; EtOH, ethanol; Sau, sauchinone; Sau 2.5:2.5 mg/kg/day Sau; Sau 7.5, $7.5 \mathrm{mg} / \mathrm{kg} /$ day Sau; Sau25, $25 \mathrm{mg} / \mathrm{kg} /$ day Sau. \#\#\# $p<0.001$ versus the S/vehicle/S group; $\$ \$ \$ p<0.001$ versus the $S /$ vehicle/EtOH group; $@ @ @<0.001$ versus the EtOH/vehicle/S group (one-way ANOVA followed by the Newman-Keuls post hoc test).

all $p>0.05$; Figure 2). Additionally, an acute injection of 2.5, 7.5 , or $25 \mathrm{mg} / \mathrm{kg}$ Sau alone did not significantly alter locomotor activity (data not shown).

\subsection{Effects of Sau on EtOH Withdrawal-Induced Anxiety-Like} Behavior. As depicted in Figure 3, EtOHW rats displayed anxiety-like behavior in the EPM when tested 3 days after the final dose of EtOH. Namely, EtOHW rats entered the open arms less frequently and spent less time in them than salinetreated control rats (\%entry open arms: $F_{5,42}=27.87, p<0.001$; saline/vehicle versus $\mathrm{EtOH} /$ vehicle, $p<0.001$; \%time open arms: $_{\text {: }}$ $F_{5,42}=28.61, p<0.001$; saline/vehicle versus EtOH/vehicle, $p<0.001$ ). However, Sau at 7.5 and 25 (but not 2.5) $\mathrm{mg} / \mathrm{kg} /$ day reversed these anxiety-like behaviors (\%entry open arms: EtOH/ vehicle versus $\mathrm{EtOH} / \mathrm{Sau} 7.5, p<0.001 ; \mathrm{EtOH} /$ vehicle versus $\mathrm{EtOH} / \mathrm{Sau} 25, p<0.001 ; \mathrm{EtOH} /$ vehicle versus $\mathrm{EtOH} / \mathrm{Sau} 2.5$, $p>0.05 ; \%$ time $_{\text {open arms: }} \mathrm{EtOH} /$ vehicle versus $\mathrm{EtOH} / \mathrm{Sau} 7.5$, $p<0.001 ; \mathrm{EtOH} /$ vehicle versus EtOH/Sau25, $p<0.001 ; \mathrm{EtOH} /$ vehicle versus $\mathrm{EtOH} / \mathrm{Sau} 2.5, p>0.05)$, and the effects were dose-dependent (\%entry open arms: $\mathrm{EtOH} / \mathrm{Sau} 7.5$ versus $\mathrm{EtOH} /$ Sau25, $p<0.05$; \%time open arms: EtOH/Sau7.5 versus EtOH/ Sau25, $p<0.05$ ). Additionally, $25 \mathrm{mg} / \mathrm{kg} / \mathrm{day}$ of Sau alone did not affect anxiety-like behaviors in the EPM (\%entry ${ }_{\text {open arms: }}$ saline/vehicle versus saline/Sau25, $p>0.05 ; \%$ time $_{\text {open arms: }}$ : saline/vehicle versus saline/Sau25, $p>0.05$; Figure 3).

\subsection{Effects of Sau on Plasma CORT Levels during EtOHW.} Plasma levels of CORT, a hormone indicative of anxiety in rats, increase during EtOHW when challenged by stressors. As shown in Figure 4, plasma CORT levels were significantly increased in EtOH-treated control rats relative to salinetreated controls $\left(F_{5}, 36=24.00, p<0.001\right.$; saline/vehicle $(n=7)$ versus $\mathrm{EtOH} /$ vehicle $(n=7), p<0.001)$, indicating a 


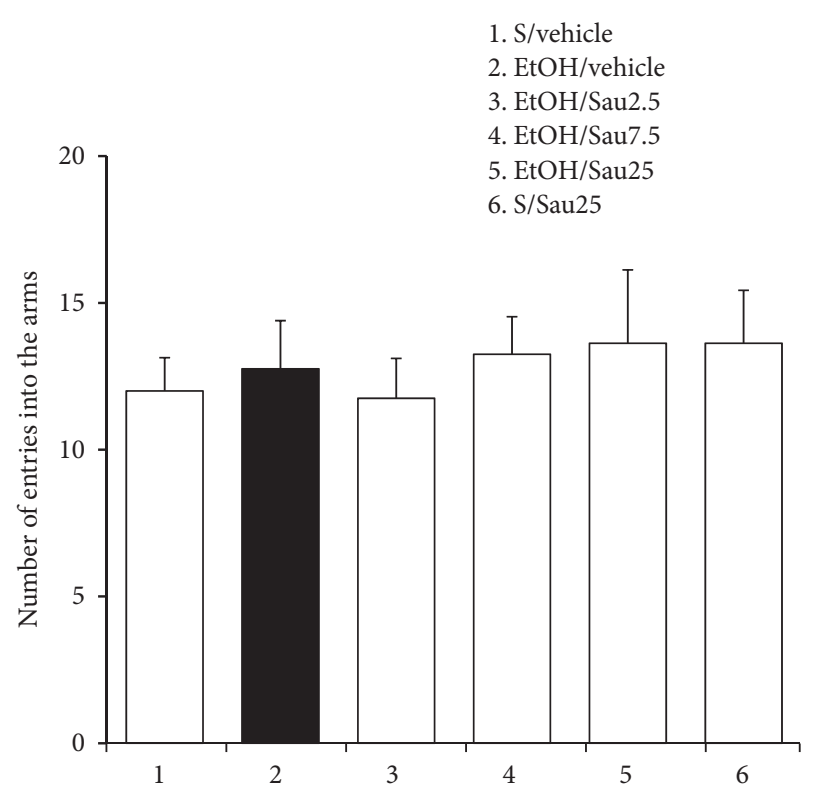

(a)

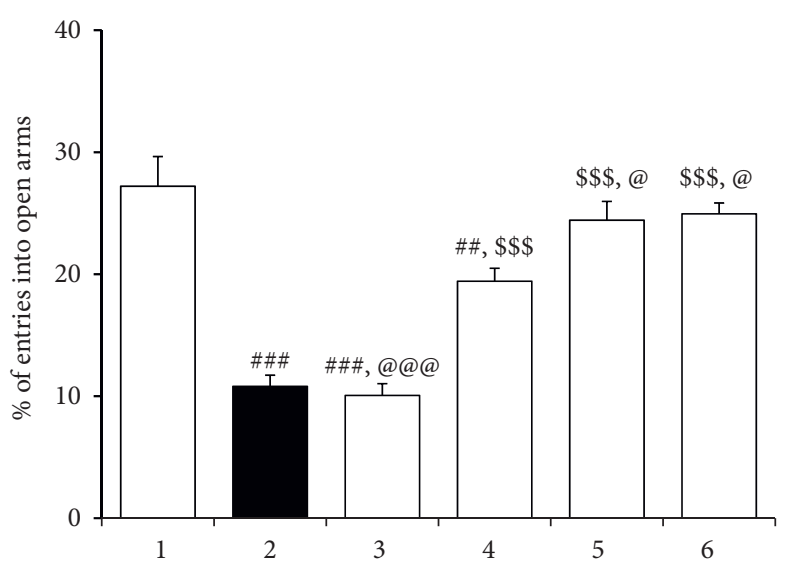

(b)

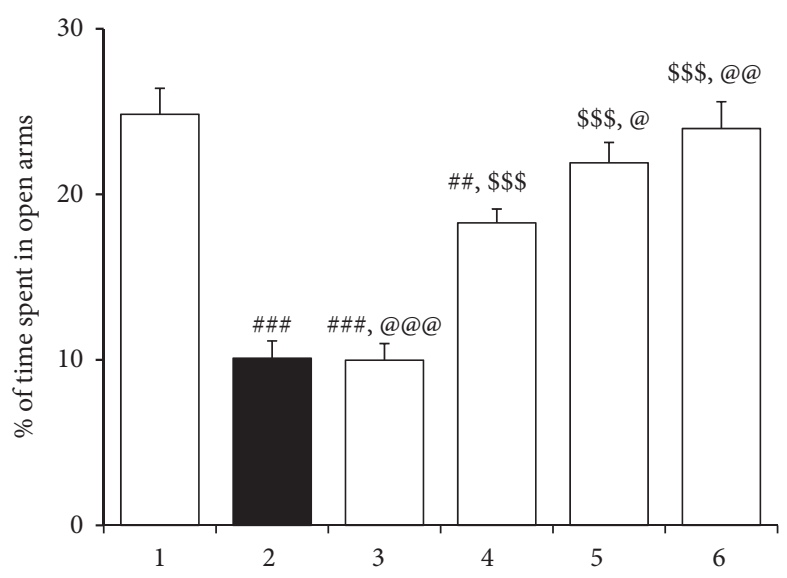

(c)

FIgURE 3: Effects of Sau on EtOH withdrawal-induced anxiety-like behavior. EtOHW produced anxiety-like behaviors in rats when tested 3 days after the final dose of $\mathrm{EtOH}$, but these behaviors were attenuated by Sau treatment during withdrawal. (a) Total number of entries into open and closed arms of the EPM by rats. (b) Percentage of numbers of entries into open arms of the EPM by rats. (c) Percentage of time spent in open arms by rats. All data are presented as a mean $\pm \mathrm{SEM}(n=8)$. S, saline; EtOH, ethanol; Sau, sauchinone; Sau $2.5,2.5 \mathrm{mg} / \mathrm{kg} / \mathrm{day}$ Sau; Sau 7.5: $7.5 \mathrm{mg} / \mathrm{kg} /$ day Sau; Sau 25, $25 \mathrm{mg} / \mathrm{kg} /$ day Sau. \#\# $p<0.01$ and \#\#\# $p<0.001$ versus the S/vehicle group; $\$ \$ \$ p<0.001 \mathrm{versus} \mathrm{the}$ EtOH/vehicle group; @ $p<0.05$, @@ $p<0.01$, and @@@ $p<0.001$ versus the EtOH/Sau7.5 group (one-way ANOVA followed by the Newman-Keuls post hoc test).

state of anxiety in rats during EtOHW. However, the increase was attenuated by Sau treatment at doses of 7.5 and 25 (but not 2.5 ) $\mathrm{mg} / \mathrm{kg} / \mathrm{day}$ (EtOH/vehicle versus EtOH/Sau7.5 $(n=7), p<0.001 ; \mathrm{EtOH} /$ vehicle versus EtOH/Sau25 $(n=7)$, $p<0.001 ; \mathrm{EtOH} /$ vehicle versus EtOH/Sau2.5 $(n=7)$, $p>0.05)$, analogous to its effects in the EPM. Sau alone at $25 \mathrm{mg} / \mathrm{kg} /$ day did not influence plasma CORT levels (saline/ vehicle versus saline/Sau25 $(n=7), p>0.05$; Figure $4(\mathrm{a})$ ).

\subsection{Effects of Sau on NO Levels in the BNST during EtOHW.} As seen in Figure 4(b), 3 days after the final EtOH dose, NO production in the BNST was significantly increased in EtOHtreated control rats compared to their saline-treated counterparts
$\left(F_{5,30}=16.20, p<0.001\right.$; saline/vehicle $(n=6)$ versus EtOH/ vehicle $(n=6), p<0.001)$, implying elevated NO signaling in the BNST during EtOHW. However, this enhanced signaling was blocked by treatment with Sau at 7.5 or $25 \mathrm{mg} / \mathrm{kg} / \mathrm{day}(\mathrm{EtOH} /$ vehicle versus EtOH/Sau7.5 $(n=6), p<0.001 ; \mathrm{EtOH} /$ vehicle versus $\mathrm{EtOH} / \mathrm{Sau} 25(n=6), p<0.001 ; \mathrm{EtOH} /$ vehicle versus EtOH/Sau2.5 $(n=6), p>0.05)$. Treatment with Sau alone at $25 \mathrm{mg} / \mathrm{kg} /$ day did not significantly affect BNST NO production (saline/vehicle versus saline/Sau25 ( $n=6), p>0.05$; Figure 4(b)).

3.5. Effect of Sau on the Protein Expression of CRF, iNOS, and $n N O S$ in the BNSTduring EtOHW. CRF protein levels in the BNST have previously been reported to be positively 


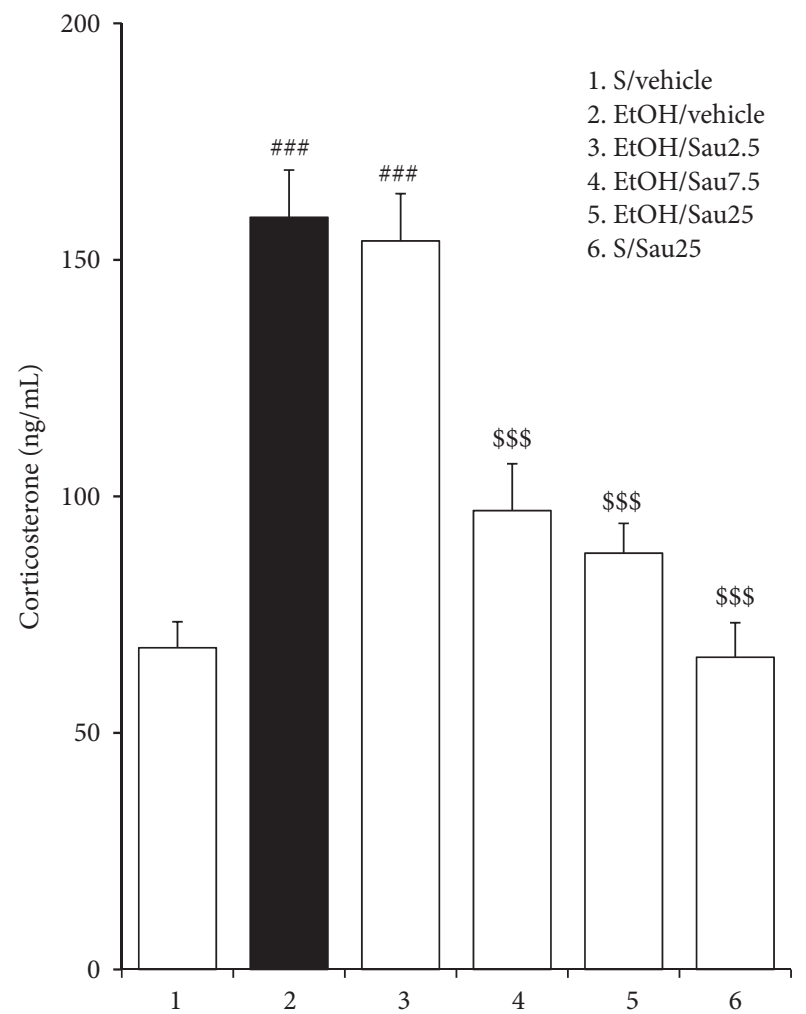

(a)

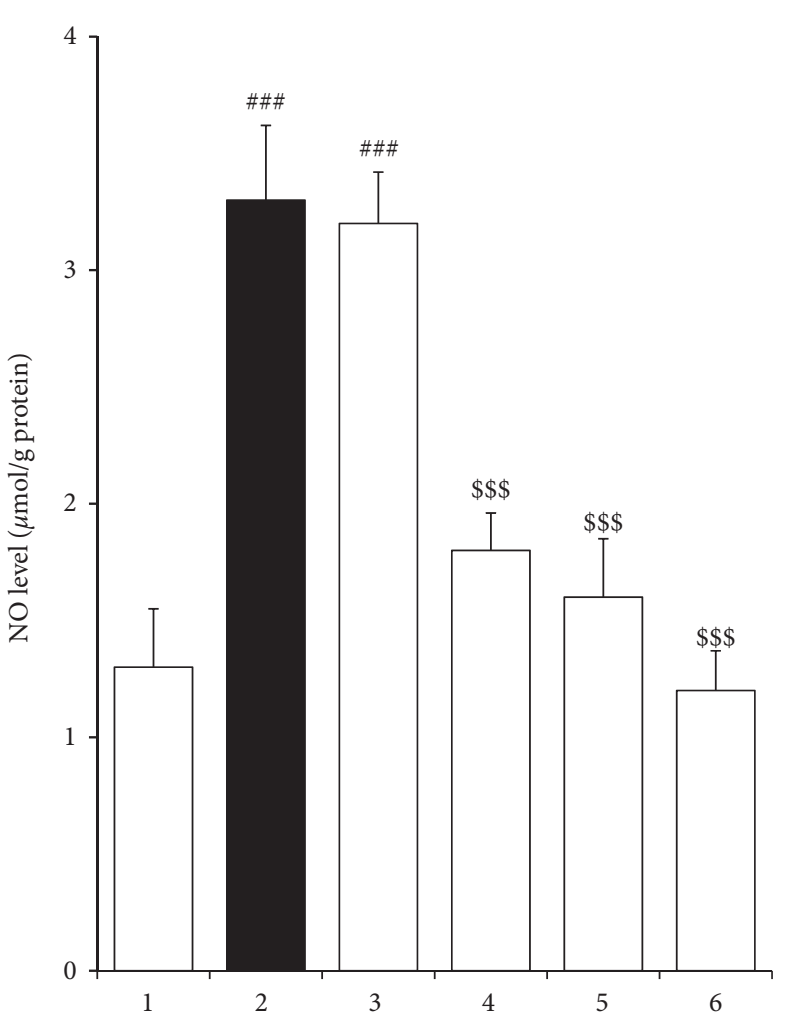

(b)

FIgUre 4: Effects of Sau on plasma CORT levels and NO production in the BNST during EtOHW. Withdrawal from repeated EtOH administration elevated plasma CORT concentrations and NO levels in the BNST in rats, which were both prevented by Sau treatment. All data are presented as means \pm SEM ( $n=7$ for CORT, $n=6$ for NO). S, saline; EtOH, ethanol; Sau, sauchinone; Sau 2.5, $2.5 \mathrm{mg} / \mathrm{kg} / \mathrm{day}$ Sau; Sau 7.5, $7.5 \mathrm{mg} / \mathrm{kg} /$ day Sau; Sau 25, $25 \mathrm{mg} / \mathrm{kg} /$ day Sau. \#\#\# $p<0.001$ versus the S/vehicle group; $\$ \$ \$ p<0.001$ versus the EtOH/vehicle group (one-way ANOVA followed by the Newman-Keuls post hoc test).

correlated with plasma CORT secretion and anxiety in rats. In this study, as depicted in Figure 5, Western blot analysis showed that EtOHW enhanced CRF protein levels in the $\operatorname{BNST}\left(F_{3,16}=38.96, p<0.001\right.$; saline/vehicle $(n=5)$ versus $\mathrm{EtOH} /$ vehicle $(n=5), p<0.001)$. However, this enhancement was blocked with Sau treatment at $25 \mathrm{mg} / \mathrm{kg} /$ day $(\mathrm{EtOH} /$ vehicle versus EtOH/Sau25 $(n=5), p<0.001)$. CRF protein expression in the BNST was not affected by Sau treatment alone at $25 \mathrm{mg} / \mathrm{kg} /$ day (saline/vehicle versus saline/Sau25 $(n=5), p>0.05$; Figure 5).

Western blot analysis revealed that the bands representing the iNOS protein in the saline-treated control and saline/Sau25 groups were barely detectible (Figure 5), likely because the expression of iNOS is induced by inflammatory and immune responses. Nonetheless, protein levels of both iNOS and nNOS in the BNST were significantly increased on the third day of EtOHW (iNOS : $F_{3,16}=205.00, p<0.001$; saline/vehicle $(n=5)$ versus $\mathrm{EtOH} /$ vehicle $(n=5), p<0.001 ; \mathrm{nNOS}: F_{3,16}=56.97$, $p<0.001 ;$ saline/vehicle $(n=5)$ versus EtOH/vehicle $(n=5)$, $p<0.001)$. The increased iNOS and nNOS expression was reversed by treatment with Sau at $25 \mathrm{mg} / \mathrm{kg} /$ day (iNOS: EtOH/ vehicle versus $\mathrm{EtOH} / \mathrm{Sau} 25(n=5), p<0.001$; nNOS: $\mathrm{EtOH} /$ vehicle versus EtOH/Sau25 $(n=5), p<0.001)$. Finally, Sau $(25 \mathrm{mg} / \mathrm{kg} /$ day $)$ treatment alone affected neither iNOS nor nNOS protein expression in the BNST (iNOS, saline/vehicle versus saline/Sau25 $(n=5), p>0.05 ;$ nNOS, saline/vehicle versus saline/Sau25 $(n=5), p>0.05$; Figure 5).

3.6. Effect of Sau on the mRNA Expression of $i N O S$ and $n N O S$ in the BNST during EtOHW. Similar to the abovementioned Western blot analysis, iNOS mRNA expression in the BNST was not observed in either the saline/vehicle or saline/Sau25 group (Figure 6). However, qPCR assays showed that EtOHW induced and elevated the mRNA expression of iNOS and nNOS in the BNST, effects that were significantly inhibited by treatment with Sau $\left(25 \mathrm{mg} / \mathrm{kg} /\right.$ day) during EtOHW (iNOS: $\mathrm{t}_{10}=14.25, \mathrm{EtOH} /$ vehicle $(n=6)$ versus EtOH/Sau25 $(n=6), p<0.001 ; \mathrm{nNOS}: F_{3}$, ${ }_{20}=20.65, p<0.001 ;$ saline/vehicle $(n=6)$ versus EtOH/vehicle $(n=6), p<0.001 ; \mathrm{EtOH} /$ vehicle versus $\mathrm{EtOH} / \mathrm{Sau} 25(n=6)$, $p<0.001)$. Sau $(25 \mathrm{mg} / \mathrm{kg} /$ day $)$ treatment alone did not affect nNOS mRNA expression in the BNST (nNOS: saline/vehicle versus saline/Sau25 $(n=6), p>0.05$; Figure 6).

3.7. Effect of Sau on the Protein Expression of nNOS Induced by $\mathrm{H}_{2} \mathrm{O}_{2}$ in PC12 Cells. Previous studies have reported that the cell viability of PC12 cells significantly decreases when incubated for 24 hours with $\mathrm{H}_{2} \mathrm{O}_{2}$ at doses greater than $100 \mu \mathrm{M}$ $[38,39]$, which was also confirmed by our preliminary experiment. Therefore, in this study, the PC12 cells were 


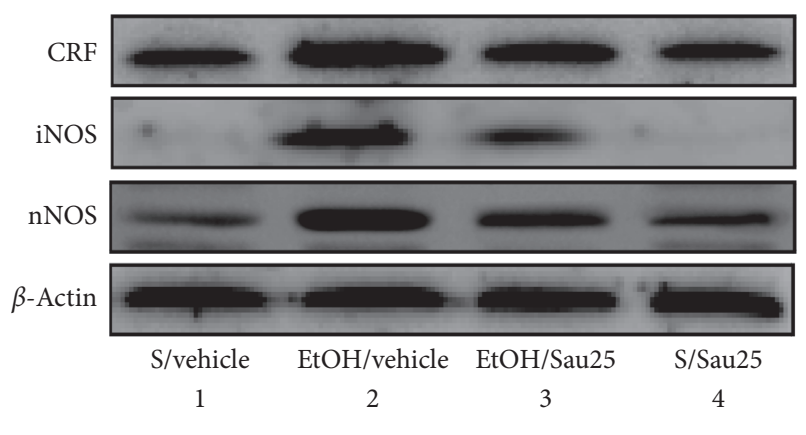

(a)

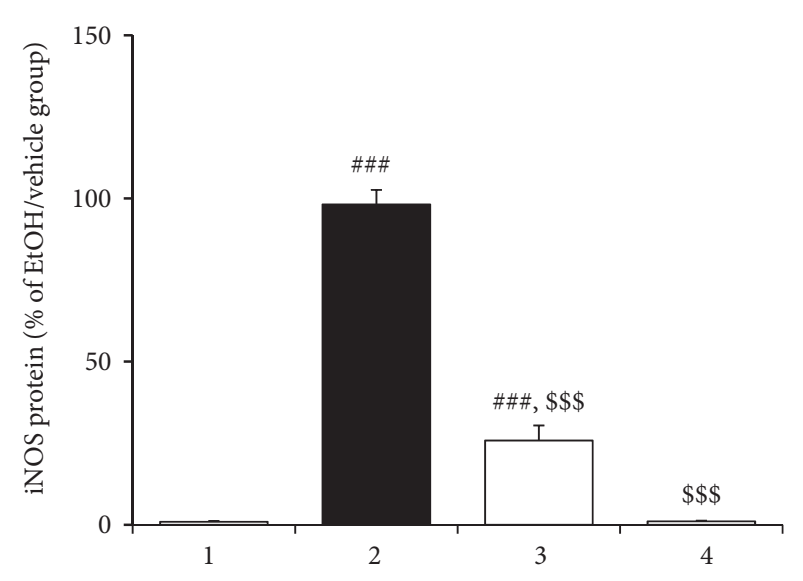

(c)

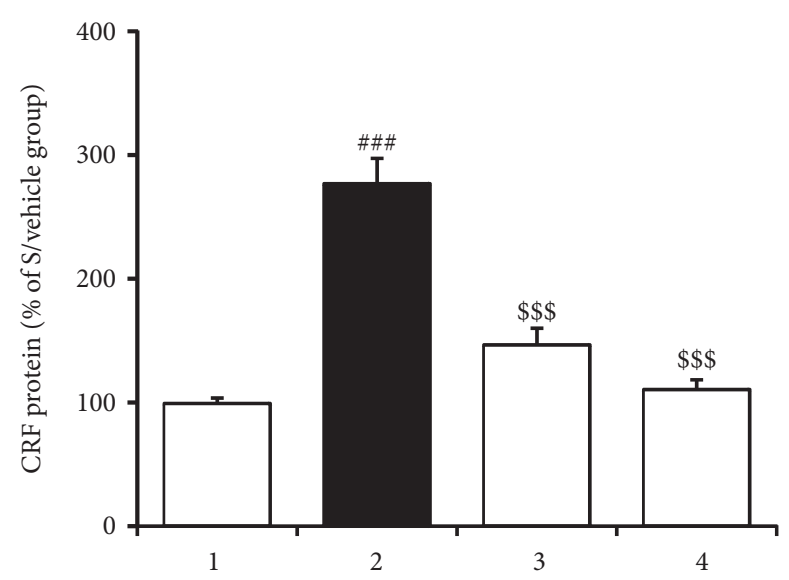

(b)

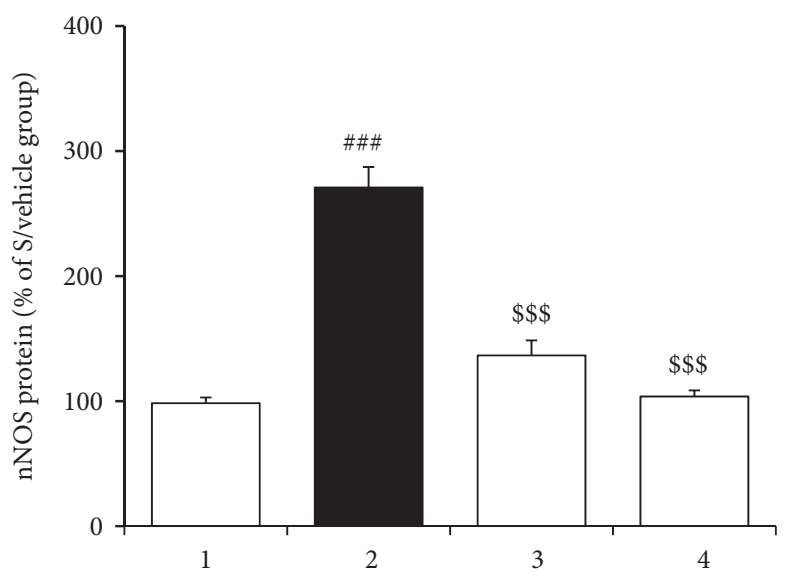

(d)

FIGURE 5: (a) Effect of Sau on the protein expression of CRF, iNOS, and nNOS in the BNST during EtOHW. Immediately after the behavioral test in the EPM, Western blotting analysis was conducted to detect the interested proteins. (b) CRF, (c) iNOS, and (d) nNOS; all data are presented as a mean \pm SEM $(n=5)$. S, saline; EtOH, ethanol; Sau, sauchinone; Sau 25, $25 \mathrm{mg} / \mathrm{kg} /$ day Sau. \#\#\# $p<0.001$ versus the S/vehicle group; $\$ \$ \$ p<0.001$ versus the EtOH/vehicle group (one-way ANOVA followed by the Newman-Keuls post hoc test).

incubated with $75 \mu \mathrm{M} \mathrm{H} \mathrm{H}_{2} \mathrm{O}_{2}$, which did not significantly influence cell viability. The effects of Sau on oxidative stressinduced nNOS expression in these cells were determined with Western blot assays.

Neither $75 \mu \mathrm{M} \mathrm{H}_{2} \mathrm{O}_{2}$ nor Sau $(3,10$, and $30 \mu \mathrm{M})$ significantly affected cell viability $\left(F_{5,30}=0.76, p>0.05\right.$; Figure 7$)$. $\mathrm{H}_{2} \mathrm{O}_{2}$ stimulation increased nNOS protein levels in PC12 cells (nNOS: $F_{5,24}=20.08, p<0.001$; vehicle/vehicle $(n=5)$ versus vehicle $/ \mathrm{H}_{2} \mathrm{O}_{2}(n=5), p<0.001$; Figure 7$)$. However, similar to the BNST, this increase was attenuated with Sau treatment at 3, 10 , or $30 \mu \mathrm{M}$ (vehicle $/ \mathrm{H}_{2} \mathrm{O}_{2}$ versus $\mathrm{Sau} 03 / \mathrm{H}_{2} \mathrm{O}_{2} \quad(n=5)$, $p<0.001$; vehicle $/ \mathrm{H}_{2} \mathrm{O}_{2}$ versus Sau10/ $\mathrm{H}_{2} \mathrm{O}_{2}(n=5), p<0.001$; vehicle $/ \mathrm{H}_{2} \mathrm{O}_{2}$ versus $\left.\mathrm{Sau} 30 / \mathrm{H}_{2} \mathrm{O}_{2}(n=5), p<0.001\right)$ in a dosedependent manner ( $\mathrm{Sau} 03 / \mathrm{H}_{2} \mathrm{O}_{2}$ versus Sau30/ $\mathrm{H}_{2} \mathrm{O}_{2}, p<0.05$; Figure 7). Treatment with $30 \mu \mathrm{M}$ Sau alone did not significantly change nNOS protein expression in the PC12 cells (vehicle/ vehicle versus Sau30/vehicle $(n=5), p>0.05$; Figure 7$)$.

3.8. Effect of Intra-BNST Infusions of SNP on the Anxiolytic Action of Sau during EtOHW. After intra-BNST infusions of MRS or SNP, the rats were tested in the EPM. EtOH-treated control rats displayed anxiety-like behaviors that were inhibited by treatment with Sau at $25 \mathrm{mg} / \mathrm{kg} /$ day (\%entry open arms: $F_{3}$, ${ }_{20}=9.90, p<0.001$; saline/vehicle/MRS $(n=6)$ versus EtOH/ vehicle/MRS $(n=6), p<0.001 ;$ EtOH/vehicle/MRS versus

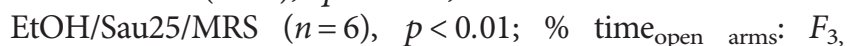
${ }_{20}=17.02, p<0.001 ;$ saline/vehicle/MRS versus EtOH/vehicle/ MRS, $p<0.001 ; \mathrm{EtOH} /$ vehicle/MRS versus EtOH/Sau25/MRS, $p<0.001$; Figure 8), consistent with the behavioral findings described above. However, the anxiolytic-like actions of Sau were abrogated when SNP was injected into the BNST after the third dose of Sau (\%entry open arms: EtOH/Sau25/MRS versus EtOH/Sau25/SNP $(n=6), p<0.05 ; \%$ time $_{\text {open arms: EtOH/ }}$ Sau25/MRS versus EtOH/Sau25/SNP, $p<0.001$; Figure 8).

\section{Discussion}

Previous studies have demonstrated that Sau improves behavioral and pathological signs of methamphetamine dependence [32, 33]; accordingly, in this study, the effects of Sau on $\mathrm{EtOH}$ dependence were evaluated using rat $\mathrm{EtOH}$ locomotor sensitization and withdrawal anxiety models. 


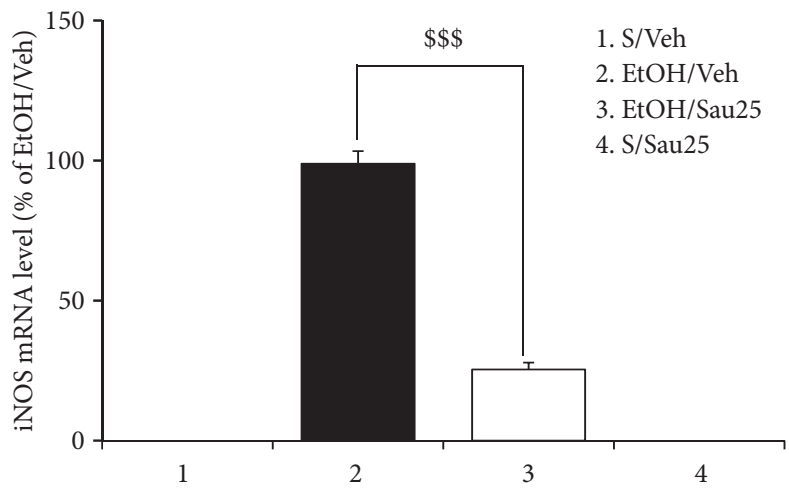

(a)

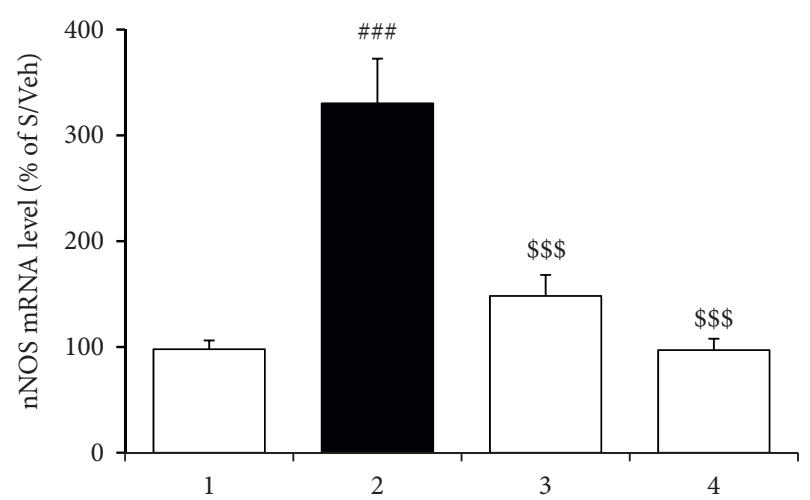

(b)

FIGURE 6: Effect of Sau on the mRNA expression of iNOS and nNOS in the BNST during EtOHW. Immediately after the behavioral test in the EPM, qPCR analysis was performed to measure the mRNA levels of iNOS and nNOS in the BNST. (a) iNOS and (b) nNOS; all data are presented as a mean \pm SEM $(n=6)$. S, saline; Veh, vehicle; EtOH, ethanol; Sau, sauchinone; Sau $25,25 \mathrm{mg} / \mathrm{kg} / \mathrm{day}$ Sau. \#\#\# $p<0.001 \mathrm{versus}$ the $\mathrm{S} /$ vehicle group; $\$ \$ \$ p 0.001$ versus the $\mathrm{EtOH} /$ vehicle group (a one-tailed unpaired $t$-test for iNOS mRNA; one-way ANOVA followed by the Newman-Keuls post hoc test for nNOS mRNA).

When rats were treated with Sau $(2.5,7.5$, and $25 \mathrm{mg} / \mathrm{kg} /$ day), daily during a 3-day EtOHW period, Sau at all three doses had no effect on EtOH locomotor sensitization. In contrast, Sau at 7.5 and 25 (but not 2.5 ) $\mathrm{mg} / \mathrm{kg} /$ day alleviated EtOHW anxiety in the EPM in a dose-dependent manner. Accordingly, Sau at 7.5 or $25 \mathrm{mg} / \mathrm{kg} /$ day blocked the elevation of plasma CORT levels and NO production in the BNST during EtOHW, and Sau at $25 \mathrm{mg} / \mathrm{kg} /$ day decreased CRF protein expression in the BNST. In the Western blot assays, Sau attenuated increases in the protein expression of both iNOS and nNOS in the BNST during EtOHW and inhibited $\mathrm{H}_{2} \mathrm{O}_{2}$-stimulated nNOS protein expression in PC12 cells. Correspondingly, Sau reduced the increased mRNA expression of iNOS and nNOS in the BNST during EtOHW. In the local infusion experiment, the injection of SNP into the BNST following Sau administration abolished the anxiolytic action of Sau in EtOHW. Taken together, these results suggest that Sau, when administered during EtOHW, can attenuate EtOHW-induced anxiety without affecting $\mathrm{EtOH}$ locomotor sensitization, and its anxiolytic effects are mediated by inhibition of NO signaling in the BNST.

Behavioral sensitization of EtOH has been reported in some rodent strains, such as DBA/2J mice and SD rats $[36,40]$. For example, Hoshaw and Lewis reported locomotor sensitization in SD rats challenged by EtOH 21 days after a 15-day period of i.p. EtOH administration [36]. In this study, when challenged by EtOH 3 days after a 28-day $\mathrm{EtOH}$ administration protocol, EtOH-pretreated rats traveled greater distances than saline-pretreated rats, indicating EtOH locomotor sensitization. This behavioral sensitization is neurochemically supported by our previous study reporting that $\mathrm{SD}$ rats undergoing the same $\mathrm{EtOH}$ regime as that used in this study showed sensitized accumbal dopamine release when challenged with EtOH [4]. Moreover, it was previously demonstrated that Sau at 5 or $10 \mathrm{mg} / \mathrm{kg}$ attenuated methamphetamine-induced hyperlocomotion, with the latter dose also blocking methamphetamine-conditioned place preference [32]. However, in this study, none of the three doses $(2.5,7.5$, and $25 \mathrm{mg} / \mathrm{kg} /$ day $)$ of Sau significantly influenced EtOH locomotor sensitization. The development of EtOH locomotor sensitization is divided into three phases: the acquisition phase (daily EtOH intake), the incubation phase (the withdrawal period), and the expression phase (immediately after EtOH challenge). Among these, the incubation phase mimics the increasing intensity of EtOH cravings after abstinence; hence, Sau was administered to rats during EtOHW in this study. The results from this study indicated that Sau treatment during EtOHW cannot block the development of EtOH locomotor sensitization, that is, it cannot block the positive reinforcing effects of EtOH during abstinence. These results also implied that the mechanisms underlying positive reinforcement-related behavioral changes likely differ between $\mathrm{EtOH}$ and methamphetamine.

Rats show increased anxiety-like behaviors in the EPM during a certain period of EtOHW [41]. The EtOHW paradigm used in this study has been well validated [12, 42]. Accordingly, substantial anxiety-like behaviors in the EPM in EtOHW rats were observed. EtOHW rats visited the open arms less frequently and spent less time in them compared to saline-treated control rats. These anxiety-like behaviors were dose-dependently reversed with Sau treatment at 7.5 or $25 \mathrm{mg} / \mathrm{kg} /$ day, that is, Sau increased the number of entries made and the duration of time spent in the open arms, by EtOHW rats. These results indicated that Sau administered during EtOHW can attenuate withdrawal-induced anxiety. Although Sau itself has not yet been reported to exert anxiolytic actions, lignans isolated from Schisandra chinensis fruit have been demonstrated to reduce restraint stress-induced anxiety [43]. Furthermore, in mice, Sau has been shown to rescue repeated methamphetamine-induced damage to striatal dopaminergic terminals [33], implying that it may alleviate the emotional disturbances induced by drug abuse. In this study, the anxiolytic effects of Sau during EtOHW were further corroborated by the finding that Sau treatment blocked EtOHW-induced increases in the plasma 


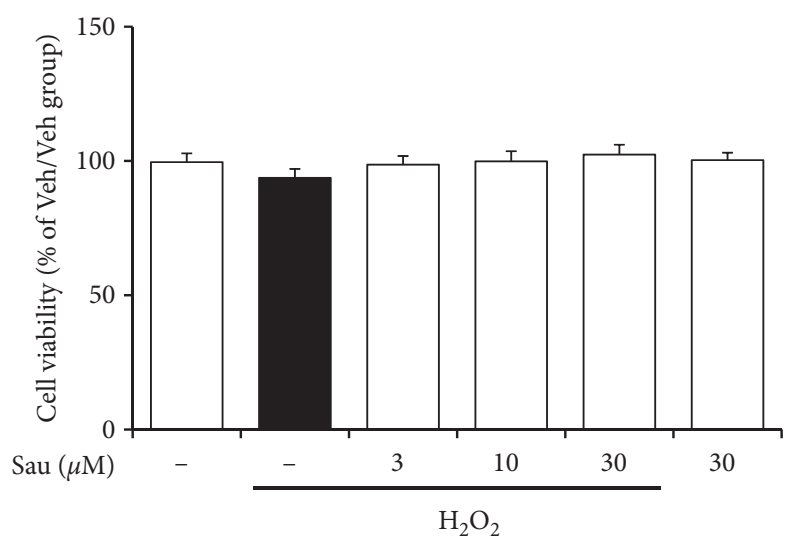

(a)

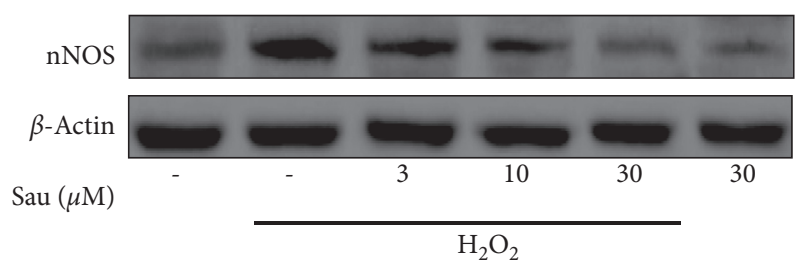

(b)

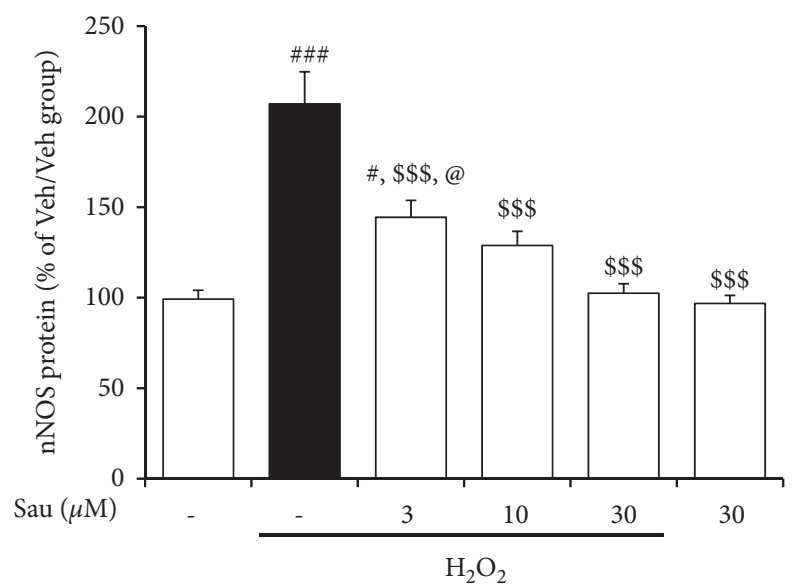

(c)

Figure 7: Effect of Sau on the protein expression of nNOS induced by $\mathrm{H}_{2} \mathrm{O}_{2}$ in PC12 cells. PC12 cells were pretreated with 3, 10, and $30 \mu \mathrm{M}$ of Sau for $60 \mathrm{~min}$ and then incubated with $75 \mu \mathrm{M}$ of $\mathrm{H} 2 \mathrm{O} 2$ for $24 \mathrm{~h}$ (a) Cell viability was examined with the MTT assay. (b), (c) Western blotting analysis was carried out using PC12 cell lysates. Veh, vehicle; Sau, sauchinone. $\# p<0.001$ and \#\#\# $p<0.001$ versus the Veh/Veh group; $\$ \$ \$ p<0.001$ versus the Veh/ $\mathrm{H}_{2} \mathrm{O}_{2}$ group; $@ p<0.05$ versus the $30 \mu \mathrm{M} \mathrm{Sau} / \mathrm{H}_{2} \mathrm{O}_{2}$ group (one-way ANOVA followed by the Newman-Keuls post hoc test).

CORT concentration and CRF protein level in the BNST; oversecretion of CORT and CRF in blood and the BNST, respectively, are the hormonal and neurochemical hallmarks of anxiety in rats $[12,44]$. Taken together, these results indicate that Sau inhibits EtOHW-induced anxiety.

The BNST is a key brain structure in the anxiety-like behaviors induced in rodents by drugs of abuse, and these anxiety-like behaviors are mediated by enhanced CRF signaling in the BNST $[44,45]$. The BNST is innervated by a variety of neurotransmitter, neuromodulator, and neuropeptide systems that modulate CRF signaling and therefore affect the manifestation of anxiety states $[46,47]$. Inhibition of neural NO production has anxiolytic effects, and the neural NO system modulates central CRF signaling [23, 48]. Indeed, Faria et al. reported that increased NO production in the BNST induced anxiety that was mediated by the CRF/ CRF1R (CRF1 receptor) signaling pathway [20]. In the present study, EtOHW promoted NO production in the BNST; this effect was reversed by Sau treatment (7.5 or $25 \mathrm{mg} / \mathrm{kg} /$ day), similar to how Sau inhibited CRF protein expression in the BNST. A previous study reported that Sau reduced lipopolysaccharide-stimulated NO production in microglia [35]. Taken together, these findings indicate that the anxiolytic effects of Sau may be mediated by the NO signaling pathway in the BNST.

NO production is catalyzed by three NOS isoforms: nNOS, endothelial NOS (eNOS), and iNOS. nNOS and eNOS are constitutively expressed, while the expression of iNOS is induced by inflammatory and immune responses. iNOS is mainly responsible for the amount of NO production [49]. In this study, EtOHW increased both the mRNA and protein expression of iNOS in the BNST, indicating enhanced NO production and corroborating the findings of Bonassori et al. who reported that increased neural iNOS activity was associated with EtOHW-induced anxiety [50]. Bonassori et al. also observed that nNOS, but not eNOS, is involved in EtOHW anxiety [51]. Likewise, in this study, EtOHW significantly elevated nNOS gene and protein expression in the BNST, without affecting eNOS expression (data not shown). However, treatment with $25 \mathrm{mg} / \mathrm{kg} /$ day Sau did attenuate EtOHW-induced increases in the mRNA and protein expression of both iNOS and nNOS. 


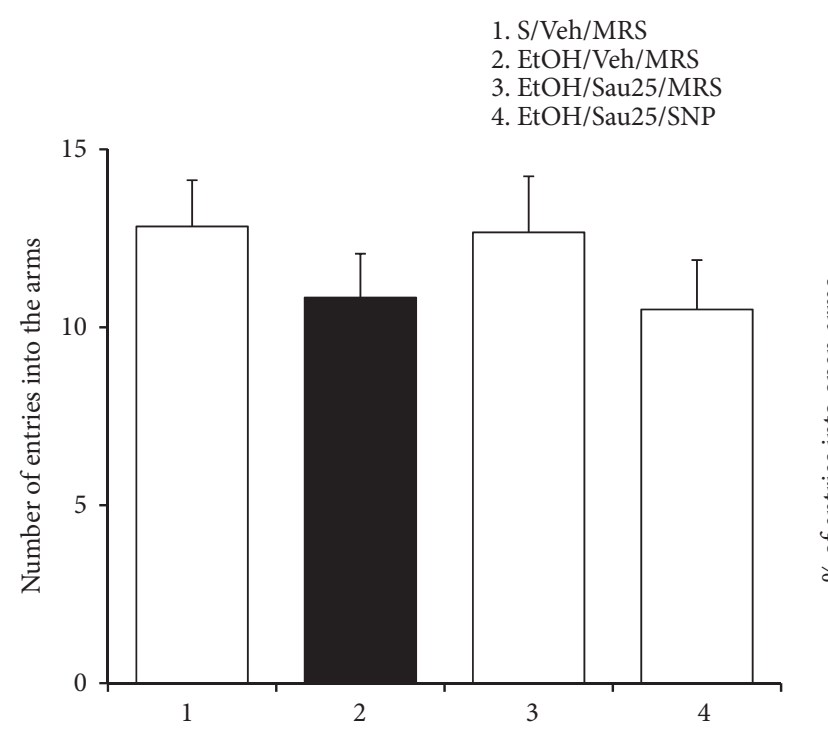

(a)

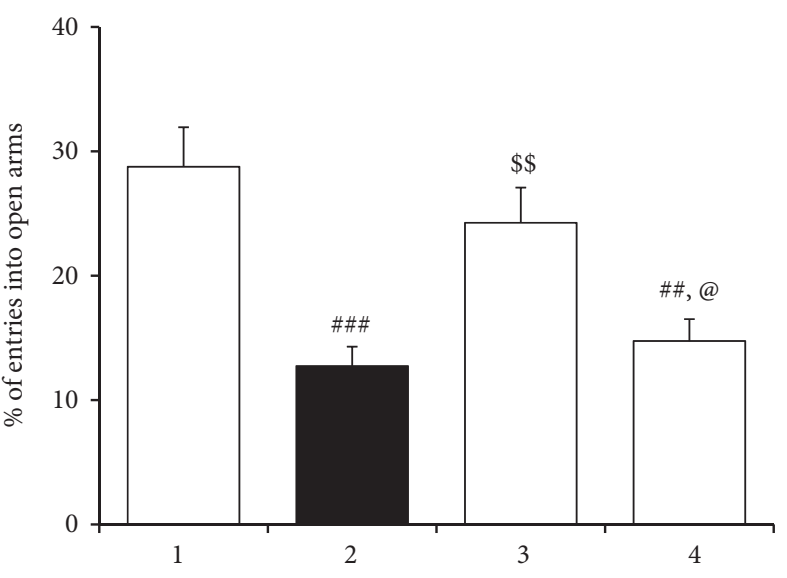

(b)

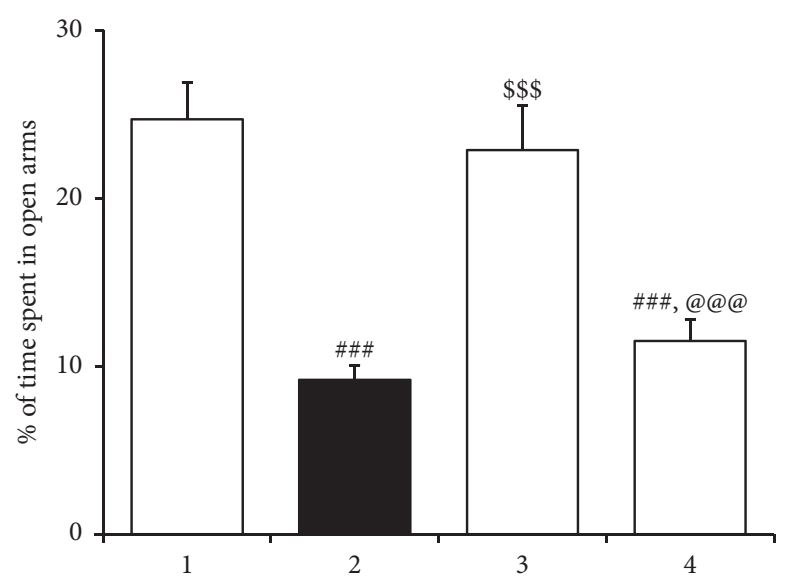

(c)

FIGURE 8: Effect of intra-BNST infusions of SNP on the anxiolytic action of Sau during EtOHW. At 30 min after the third dose of $25 \mathrm{mg} / \mathrm{kg} / \mathrm{dad}$ Sau, the rats received bilateral intra-BNST infusions of SNP and then were tested in the EPM for evaluating anxiety-like behavior. (a) Total number of entries into open and closed arms of the EPM by rats. (b) Percentage of numbers of entries into open arms of the EPM by rats. (c) Percentage of time spent in open arms by rats. All data are presented as a mean \pm SEM $(n=6)$. S, saline; EtOH, ethanol; MRS, modified Ringers' solution; Sau, sauchinone; Sau 25, $25 \mathrm{mg} / \mathrm{kg} / \mathrm{day}$ Sau. \#\# $p<0.01$ and \#\#\# $p<0.001$ versus the S/ vehicle/MRS group; $p<0.01$ and $\$ \$ \$ p<0.001$ versus the EtOH/vehicle/MRS group; $@ p<0.05$ and $@ @ @ p<0.001$ versus the EtOH/ Sau25/MRS group (one-way ANOVA followed by the Newman-Keuls post hoc test).

The inhibitory effect of Sau on iNOS has been well documented in in vitro experiments using Raw264.7 (a murine macrophage cell line) and BV2 cells (a murine microglial cell line) [29,35]; however, its action on nNOS function was previously unknown. Hence, this study was the first to report that Sau inhibited nNOS expression in vivo. To further elucidate this effect and because excessive oxidative stress during EtOHW contributes to affective disorders [52], neuronal PC12 cells were used, with $\mathrm{H}_{2} \mathrm{O}_{2}$ acting as an oxidative stressor. $\mathrm{H}_{2} \mathrm{O}_{2}$ stimulation increased nNOS protein expression in PC12 cells $[38,39]$, which was dose-dependently inhibited by Sau at doses of 3,10, and $30 \mu \mathrm{M}$ in the present study. These results indicated that Sau may inhibit the expression of iNOS and nNOS in the BNST during
EtOHW to reduce NO production, thereby mediating its anxiolytic effects.

Finally, the role of NO in the BNST on the anxiolytic effect of Sau during EtOHW was pharmacologically tested. Infusions of SNP into the BNST after Sau administration blocked the anxiolytic effects of Sau in the EPM. This observation, together with the results from the abovementioned biochemical assays, indicated that Sau attenuates EtOHW anxiety by inhibiting NOS-NO-CRF signaling in the BNST.

In summary, this study found that Sau treatment during withdrawal mitigated EtOHW anxiety, but did not influence EtOH locomotor sensitization. Moreover, the anxiolytic effects of Sau were mediated by modulation of NO signaling 
in the BNST. These findings provide experimental evidence that Sau can block the negative reinforcing effects of EtOH and therefore may be a candidate for alcoholism treatment. Given that the dependence induced by some drugs of abuse, such as nicotine and morphine, also involves central NO, and future research on the effects of Sau on these drugs may be fruitful.

\section{Data Availability}

The data that support the findings of this study are statistically analyzed and included within the article and are available from the corresponding author upon request.

\section{Conflicts of Interest}

The authors declare that they have no conflicts of interest.

\section{Authors' Contributions}

Yu Jiao and Sang Chan Kim contributed equally to this work. Rongjie Zhao, Sang Chan Kim, and Zhenglin Zhao designed the research; Yu Jiao, Sang Chan Kim, Yuhua Wang, Tong Wu, Haifeng Jin, Sook Jahr Park, and Bong Hyo Lee conducted the experiments; Chul Won Lee and Chae Ha Yang did the statistical analysis; Rongjie Zhao, Zhenglin Zhao, and Hee Young Kim wrote the article.

\section{Acknowledgments}

This work was supported by the Basic Research Foundation of the Education Department of Heilongjiang Province, China (2017-QYKYYWF-0750 and 2019-KYYWF-1232), and the National Research Foundation of Korea (2018R1A5A2025272), Korea.

\section{References}

[1] M. Heilig, E. Augier, S. Pfarr, and W. H. Sommer, "Developing neuroscience-based treatments for alcohol addiction: a matter of choice?" Translational Psychiatry, vol. 9, no. 1, p. 255, 2019.

[2] G. F. Koob, A. J. Roberts, G. Schulteis et al., "Neurocircuitry targets in ethanol reward and dependence," Alcoholism: Clinical and Experimental Research, vol. 22, no. 1, pp. 3-9, 1998.

[3] N. J. Grahame, K. Rodd-Henricks, T. K. Li, and L. Lumeng, "Ethanol locomotor sensitization, but not tolerance correlates with selection for alcohol preference in high- and low-alcohol preferring mice," Psychopharmacology (Berl), vol. 151, no. 2-3, pp. 252-260, 2000.

[4] R. J. Zhao, S. S. Yoon, B. H. Lee et al., "Acupuncture normalizes the release of accumbal dopamine during the withdrawal period and after the ethanol challenge in chronic ethanol-treated rats," Neuroscience Letters, vol. 395, no. 1, pp. 28-32, 2006.

[5] D. B. Newlin and J. B. Thomson, "Chronic tolerance and sensitization to alcohol in sons of alcoholics," Alcoholism: Clinical and Experimental Research, vol. 15, no. 3, pp. 399405, 1991.

[6] R. Camarini and R. M. Pautassi, "Behavioral sensitization to ethanol: neural basis and factors that influence its acquisition and expression," Brain Research Bulletin, vol. 125, pp. 53-78, 2016.

[7] I. Shim, J. I. Javaid, D. Wirtshafter et al., "Nicotine-induced behavioral sensitization is associated with extracellular dopamine release and expression of c-Fos in the striatum and nucleus accumbens of the rat," Behavioural Brain Research, vol. 121, no. 1-2, pp. 137-147, 2001.

[8] A. Imperato and G. Di Chiara, "Preferential stimulation of dopamine release in the nucleus accumbens of freely moving rats by ethanol," Journal of Pharmacology and Experimental Therapeutics, vol. 239, no. 1, pp. 219-228, 1986.

[9] F. Weiss, R. Ciccocioppo, L. H. Parsons et al., "Compulsive drug-seeking behavior and relapse. neuroadaptation, stress, and conditioning factors," Annals of The New York Academy of Sciences, vol. 937, no. 1, pp. 1-26, 2001.

[10] M. Heilig, M. Egli, J. C. Crabbe, and H. C. Becker, "Acute withdrawal, protracted abstinence and negative affect in alcoholism: are they linked?" Addiction Biology, vol. 15, no. 2, pp. 169-184, 2010.

[11] C. A. Allan, "Alcohol problems and anxiety disorders-a critical review," Alcohol and Alcoholism (Oxford, Oxfordshire), vol. 30, no. 2, pp. 145-151, 1995.

[12] L. B. Li, Y. W. Kim, Y. H. Wang et al., "Methanol extract of semen Ziziphi spinosae attenuates ethanol withdrawal anxiety by improving neuropeptide signaling in the central amygdala," BMC Complementary and Alternative Medicine, vol. 19, no. 1, p. 147, 2019.

[13] G. R. Valdez, V. Sabino, and G. F. Koob, "Increased anxietylike behavior and ethanol self-administration in dependent rats: reversal via corticotropin-releasing factor-2 receptor activation," Alcoholism: Clinical and Experimental Research, vol. 28, no. 6, pp. 865-872, 2004.

[14] E. V. Sullivan and A. Pfefferbaum, "Neurocircuitry in alcoholism: a substrate of disruption and repair," Psychopharmacology, vol. 180, no. 4, pp. 583-594, 2005.

[15] G. F. Koob, "Neurocircuitry of alcohol addiction: synthesis from animal models," Handbook of Clinical Neurology, vol. 125, pp. 33-54, 2014.

[16] M. M. Huang, D. H. Overstreet, D. J. Knapp et al., "Corticotropin-releasing factor (CRF) sensitization of ethanol withdrawal-induced anxiety-like behavior is brain site specific and mediated by CRF-1 receptors: relation to stress-induced sensitization," Journal of Pharmacology and Experimental Therapeutics, vol. 332, no. 1, pp. 298-307, 2010.

[17] D. Pati, C. A. Marcinkiewcz, J. F. DiBerto, E. S. Cogan, Z. A. McElligott, and T. L. Kash, "Chronic intermittent ethanol exposure dysregulates a GABAergic microcircuit in the bed nucleus of the stria terminalis," Neuropharmacology, vol. 168, p. 107759, 2020.

[18] I. Shim, H. T. Kim, Y. H. Kim et al., "Role of nitric oxide synthase inhibitors and NMDA receptor antagonist in nicotine-induced behavioral sensitization in the rat," European Journal of Pharmacology, vol. 443, no. 1-3, pp. 119-124, 2002.

[19] Y. Itzhak and J. L. Martin, "Blockade of alcohol-induced locomotor sensitization and conditioned place preference in DBA mice by 7-nitroindazole," Brain Research, vol. 858, no. 2, pp. 402-407, 2000.

[20] M. P. Faria, T. T. Miguel, K. S. Gomes, and R. L. Nunes-deSouza, "Anxiety-like responses induced by nitric oxide within the BNST in mice: role of CRF1 and NMDA receptors," Hormones and Behavior, vol. 79, pp. 74-83, 2016.

[21] M. P. Faria, C. F. Laverde, and R. L. Nunes-de-Souza, "Anxiogenesis induced by social defeat in male mice: role of nitric oxide, NMDA, and CRF1 receptors in the medial 
prefrontal cortex and BNST," Neuropharmacology, vol. 166, p. 107973, 2020.

[22] D. I. Peregud, O. N. Vorontsova, A. A. Yakovlev, L. F. Panchenko, and N. V. Gulyaeva, "Changes in anxiety in abstinence correlate with the state of the nigrostriatal system in the rat hippocampus," Neuroscience and Behavioral Physiology, vol. 38, no. 5, pp. 443-448, 2008.

[23] N. A. Gonzaga, M. R. Batistela, D. Padovan, B. S. de Martinis, C. R. Tirapelli, and C. M. Padovan, "Ethanol withdrawal induces anxiety-like effects: role of nitric oxide synthase in the dorsal raphe nucleus of rats," Alcohol, vol. 52, pp. 1-8, 2016.

[24] A. Haj-Mirzaian, S. Amiri, H. Amini-Khoei et al., "Involvement of NO/NMDA-R pathway in the behavioral despair induced by amphetamine withdrawal," Brain Research Bulletin, vol. 139, pp. 81-90, 2018.

[25] W. Zhu, Y. Zhang, Y. Huang, and L. Lu, "Chinese herbal medicine for the treatment of drug addiction," International Review of Neurobiology, vol. 135, pp. 279-295, 2017.

[26] Z. L. Zhao, S. C. Kim, H. F. Liu et al., "Blockade of nicotine sensitization by methanol extracts of Glycyrrhizae radix mediated via antagonism of accumbal oxidative stress," BMC Complementary and Alternative Medicine, vol. 17, no. 1, p. 493, 2017.

[27] Z. Zhao, Y. W. Kim, Y. Yang et al., "Glycyrrhizae radix methanol extract attenuates methamphetamine-induced locomotor sensitization and conditioned place preference," Evidence-based Complementary and Alternative Medicine, vol. 2014, Article ID 152063, 7 pages, 2014.

[28] G. Liu, Z. Zhao, M. Shen et al., "A review of traditional uses, phytochemistry, and pharmacological properties of the genus Saururus," The American Journal of Chinese Medicine, vol. 48, no. 1, pp. 47-76, 2020.

[29] A. K. Lee, S. H. Sung, Y. C. Kim, and S. G. Kim, "Inhibition of lipopolysaccharide-inducible nitric oxide synthase, TNF- $\alpha$ and COX-2 expression by sauchinone effects on I- $\kappa \mathrm{B} \alpha$ phosphorylation, C/EBP and AP-1 activation," British Journal of Pharmacology, vol. 139, no. 1, pp. 11-20, 2003.

[30] Y. W. Kim, S. M. Lee, S. M. Shin et al., "Efficacy of sauchinone as a novel AMPK-activating lignan for preventing iron-induced oxidative stress and liver injury," Free Radical Biology and Medicine, vol. 47, no. 7, pp. 1082-1092, 2009.

[31] M. Dos Santos Maia, G. C. S. Rodrigues, N. F. de Sousa, M. T. Scotti, L. Scotti, and F. J. B. Mendonça-Junior, "Identification of new targets and the virtual screening of lignans against alzheimer's disease," Oxidative Medicine and Cellular Longevity, vol. 2020, Article ID 3098673, 19 pages, 2020.

[32] D. H. Kim, C. H. Yang, and M. Hwang, "Sauchinone blocks methamphetamine-induced hyperlocomotion and place preference in mice," Phytomedicine, vol. 20, no. 12, pp. 1071-1075, 2013.

[33] E. Y. Jang, K. A. Park, J. R. Lee, C. H. Yang, and M. Hwang, "Protective effect of sauchinone on methamphetamine-induced neurotoxicity in mice," Journal of Pharmacological Sciences, vol. 118, no. 4, pp. 531-536, 2012.

[34] A. C. May, R. L. Aupperle, and J. L. Stewart, "Dark times: the role of negative reinforcement in methamphetamine addiction," Frontiers in Psychiatry, vol. 11, p. 114, 2020.

[35] E. Y. Jang, C. H. Yang, M. H. Han, Y. H. Choi, and M. Hwang, "Sauchinone suppresses lipopolysaccharide-induced inflammatory responses through Akt signaling in BV2 cells," International Immunopharmacology, vol. 14, no. 2, pp. 188-194, 2012.
[36] B. A. Hoshaw and M. J. Lewis, "Behavioral sensitization to ethanol in rats: evidence from the Sprague-Dawley strain," Pharmacology Biochemistry and Behavior, vol. 68, no. 4, pp. 685-690, 2001.

[37] G. Paxinos and C. Watson, The Rat Brain in Stereotaxic Coordinates, Academic Press, San Diego, CA, USA, 1988.

[38] X. H. Chen, X. Zhou, X. Y. Yang et al., "Propofol protects against $\mathrm{H}_{2} \mathrm{O}_{2}$-induced oxidative injury in differentiated PC12 cells viainhibition of $\mathrm{Ca}^{2+}$-dependent NADPH oxidase," Cellular and Molecular Neurobiology, vol. 36, no. 4, pp. 541551, 2016.

[39] Y. Tang, Y. Li, G. Yu et al., "MicroRNA-137-3p protects PC12 cells against oxidative stress by downregulation of calpain-2 and nNOS," Cellular and Molecular Neurobiology, 2020.

[40] R. A. Stevenson, J. L. Hoffman, A. M. Maldonado-Devincci, S. Faccidomo, and C. W. Hodge, "MGluR5 activity is required for the induction of ethanol behavioral sensitization and associated changes in ERK MAP kinase phosphorylation in the nucleus accumbens shell and lateral habenula," Behavioural Brain Research, vol. 367, pp. 19-27, 2019.

[41] Z. Zhang, A. C. Morse, G. F. Koob, and G. Schulteis, "Doseand time-dependent expression of anxiety-like behavior in the elevated plus-maze during withdrawal from acute and repeated intermittent ethanol intoxication in rats," Alcoholism: Clinical and Experimental Research, vol. 31, no. 11, pp. 1811-1819, 2007.

[42] Z. Zhao, S. C. Kim, R. Zhao et al., “The tegmental-accumbal dopaminergic system mediates the anxiolytic effect of acupuncture during ethanol withdrawal," Neuroscience Letters, vol. 597, pp. 143-148, 2015.

[43] W.-W. Chen, R.-R. He, Y.-F. Li, S.-B. Li, B. Tsoi, and H. Kurihara, "Pharmacological studies on the anxiolytic effect of standardized Schisandra lignans extract on restraintstressed mice," Phytomedicine, vol. 18, no. 13, pp. 1144-1147, 2011.

[44] K. S. Sink, D. L. Walker, S. M. Freeman, E. I. Flandreau, K. J. Ressler, and M. Davis, "Effects of continuously enhanced corticotropin releasing factor expression within the bed nucleus of the stria terminalis on conditioned and unconditioned anxiety," Molecular Psychiatry, vol. 18, no. 3, pp. 308-319, 2013.

[45] K. L. Wills, M. V. DeVuono, C. L. Limebeer, K. Vemuri, A. Makriyannis, and L. A. Parker, " $\mathrm{CB}_{1}$ receptor antagonism in the bed nucleus of the stria terminalis interferes with affective opioid withdrawal in rats," Behavioral Neuroscience, vol. 131, no. 4, pp. 304-311, 2017.

[46] G. J. Salimando, M. Hyun, K. M. Boyt, and D. G. Winder, "BNST GluN2D-containing NMDA receptors influence anxiety- and depressive-like behaviors and ModulateCellspecific excitatory/inhibitory synaptic balance," The Journal of Neuroscience, vol. 40, no. 20, pp. 3949-3968, 2020.

[47] K. S. Sink, A. Chung, K. J. Ressler, M. Davis, and D. L. Walker, "Anxiogenic effects of CGRP within the BNST may be mediated by CRF acting at BNST CRFR1 receptors," Behavioural Brain Research, vol. 243, pp. 286-293, 2013.

[48] S. Lee, C. K. Kim, and C. Rivier, "Nitric oxide stimulates ACTH secretion and the transcription of the genes encoding for NGFI-B, corticotropin-releasing factor, corticotropinreleasing factor receptor type 1 , and vasopressin in the hypothalamus of the intact rat," The Journal of Neuroscience, vol. 19, no. 17, pp. 7640-7647, 1999.

[49] D. S. Bredt, "Endogenous nitric oxide synthesis: biological functions and pathophysiology," Free Radical Research, vol. 31, no. 6, pp. 577-596, 1999. 
[50] V. T. Bonassoli, H. Milani, and R. M. W. de Oliveira, "Ethanol withdrawal activates nitric oxide-producing neurons in anxiety-related brain areas," Alcohol, vol. 45, no. 7, pp. 641-652, 2011.

[51] V. T. Bonassoli, E. B. Contardi, H. Milani, and R. M. W. de Oliveira, "Effects of nitric oxide synthase inhibition in the dorsolateral periaqueductal gray matter on ethanol withdrawal-induced anxiety-like behavior in rats," Psychopharmacology, vol. 228, no. 3, pp. 487-498, 2013.

[52] M. Bonea, G. A. Filip, V. A. Toma et al., "The modulatory effect of metformin on ethanol-induced anxiety, redox imbalance, and extracellular matrix levels in the brains of wistar rats," Journal of Molecular Neuroscience, vol. 70, no. 12, pp. 1943-1961, 2020. 